\title{
Good things come in small packages: \\ Overcoming challenges to harness extracellular vesicles for therapeutic delivery
}

\author{
Dominique Ingato ${ }^{a}$, Jong Uk Lee ${ }^{b}$, Sang Jun Sim $^{b^{*}}$, and Young Jik Kwon ${ }^{a, b, c, d, e^{*}}$ \\ ${ }^{a}$ Department of Chemical Engineering and Materials Science, University of California, \\ Irvine, CA 92697, United States \\ ${ }^{b}$ Department of Chemical and Biological Engineering, Korea University, Seoul, Republic \\ of Korea \\ ${ }^{\mathrm{c} D e p a r t m e n t}$ of Pharmaceutical Sciences, ${ }^{\mathrm{d} D e p a r t m e n t}$ of Biomedical Engineering, and \\ ${ }^{e}$ Department of Molecular Biology and Biochemistry, \\ University of California, Irvine, CA 92697, United States
}
${ }^{*}$ Corresponding authors
S.J. Sim
706 Engineering Hall
Anamdong, Seongbuk-gu
Seoul, Republic of Korea
Tel: +82 232904853
Fax: +82 29266102

\author{
Y.J. Kwon \\ 132 Sprague Hall \\ Irvine, CA 92697 \\ Tel: +1 9498248714 \\ Fax: +1 9498244023
}




\section{Abstract}

Extracellular vesicles (EVs) hold great promise as potential therapeutic carriers. EVs are biologically active, intrinsically transporting cargo between cells. Moreover, they can be loaded with specific cargo for distribution and/or engineered to achieve enhanced uptake. Although studies have already demonstrated therapeutic delivery using EVs, various challenges must be overcome before EV technology is ready for the clinic. Since the properties of EVs are dependent upon their cell of origin and the conditions of their formation, establishing clear characterization practices is essential to ensuring reproducibility and safety. Identifying methods for mass production of EVs is crucial for achieving high EV yields necessary for clinical trials. This review introduces current theory behind EV formation and function, describes the latest methods for characterization and mass production, and discusses future opportunities for extracellular vesicles in therapeutic delivery.

Keywords: Extracellular vesicles; Exosomes; Microvesicles; Therapeutic delivery 


\section{Table of Contents}

1. Introduction

2. Extracellular vesicles (EVs)

2.1 Formation and composition

2.2 Biological function

3. Isolation and purification

3.1 Conventional strategies

3.2 Emerging devices for EV isolation

3.2.1 Immunoaffinity-based capture

3.2.2 Sieving

3.2.3 Trapping with porous structures

3.2.4 Acoustic separation

4. Characterization

4.1 Electron microscopy

4.2 Dynamic light scattering (DLS) and nanoparticle tracking analysis (NTA)

4.3 Flow cytometry

4.4 Surface plasmon resonance (SPR)

4.5 Membrane composition analysis

5. Quality control

5.1 Intravesicular contents

5.2 Membrane composition

6. Mass production

6.1 Intracellular calcium levels

6.2 External stress

6.3 Cytoskeletal fixation

7. Therapeutic loading

7.1 Loading EVs via cell of origin

7.2 Direct loading of EVs

7.2.1 Passive loading

7.2.2 Active loading

8. Potential applications of EVs in therapeutic delivery 
7.1 Gene and protein delivery

7.2 Drug delivery

7.3 Immunotherapy

9. Conclusions 


\section{Introduction}

The fields of drug delivery and gene therapy rely on nano-sized carriers for effective delivery of precious cargo to the designated target site. ${ }^{1-3}$ Therapeutic delivery agents have two key objectives: protect cargo from the harsh environment of the body and release cargo at the appropriate site without inducing immunogenic response. ${ }^{4-6}$ Both viral $^{7}$ and non-viral ${ }^{8}$ nanocarriers have been engineered to achieve effective, sitespecific delivery. Viral delivery has been used to delivery genes to target cells with relatively high efficiency. Though less efficient, non-viral carriers, such as nanocarbon assemblies $^{9}$, inorganic nanoparticles ${ }^{10,11}$, and liposomes ${ }^{12,13}$, generally have a lower potential for inducing side effects.

Nevertheless, issues with non-specific cytotoxicity, poor biocompatibility, and low efficacy of delivery still remain major challenges in the field. ${ }^{14,15}$ PEGylation is a common strategy for overcoming these issues and allowing for increased circulation times and decreased immunogenicity. However, recent studies have shown rapid clearance of PEGylated carriers after the initial injection as a result of systemic immunogenicity. ${ }^{16}$ Truly the only option for completely eliminating the potential of immune response is to use nanocarriers derived from a patient's one body.

Therefore, extracellular vesicles (EVs) have recently become an exciting option for nano-scale delivery. ${ }^{17-23}$ They invite a unique chance to harness naturally produced biological carriers for treatment of disease.$^{24}$ As diagrammed in Figure 1, extracellular vesicles offer a compelling opportunity to develop personalized therapeutic delivery carriers. ${ }^{25-29}$ The concept is relatively simple. Cells are harvested from a patient and used to produce vesicles in vitro. These vesicles are then loaded with cargo for delivery 


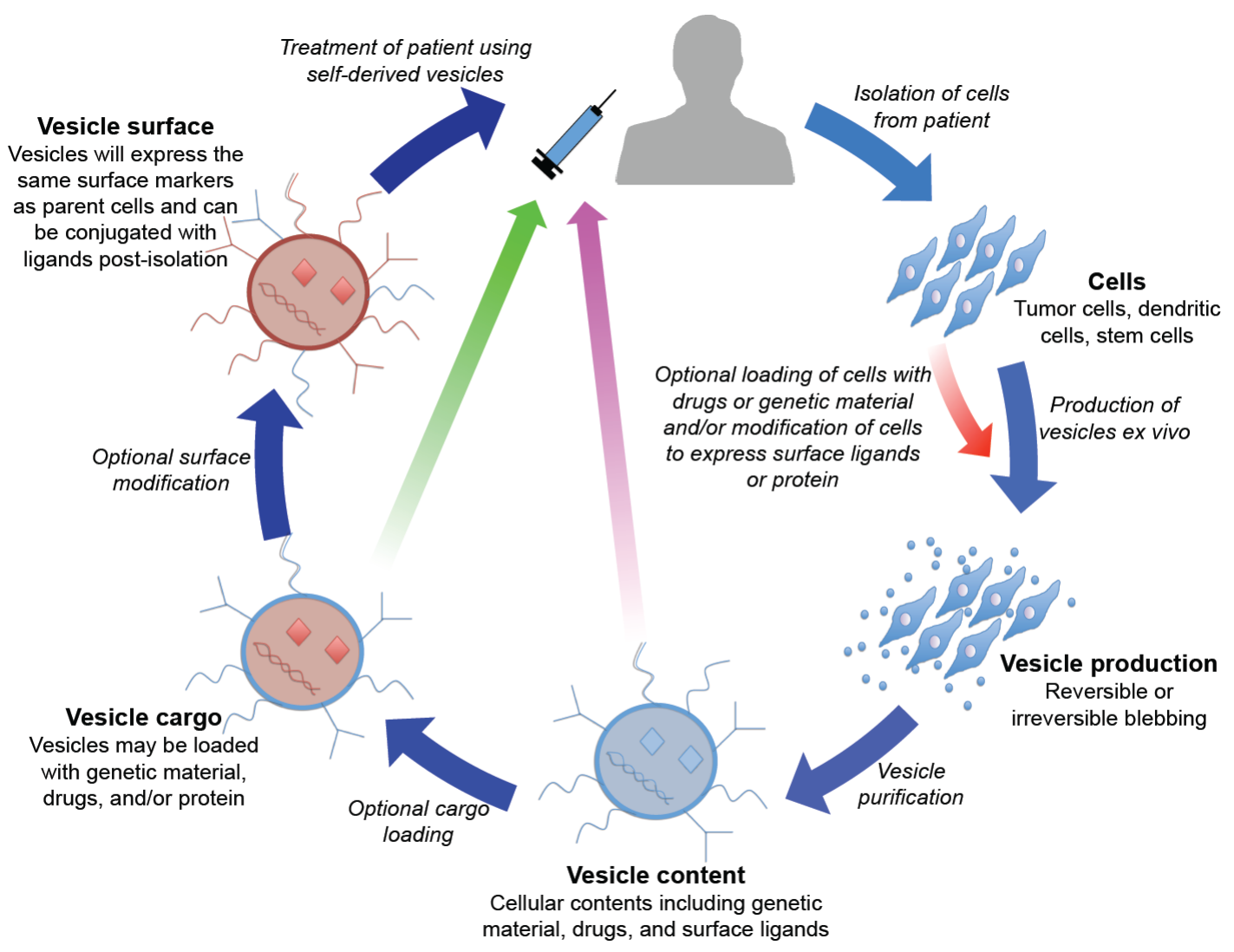

Figure 1. Schematic demonstrating the process of personalized vesicular delivery. ${ }^{21-23 \text {, }}$ 26, 27-29 A patient provides a specific primary cell line for generation of EVs. The EVs are loaded or modified as required. Finally, the EVs are used as therapeutic delivery agents for personalized therapy.

to the patient's diseased tissue; in some cases, they may undergo surface modification to achieve improved targeting. Such personalized treatment leaves low chance of inducing immunogenic response ${ }^{30}$ and could improve targeting ${ }^{31}$ based on specific surface interactions of vesicles and cells within diseased tissue.

Despite their high potential in therapeutic delivery, vesicle-based therapeutics have been slow to progress to clinical studies due to problems associated with characterization and mass production. ${ }^{32-34}$ The low yield associated with ex vivo production of vesicles is a major challenge that leads to a bottleneck in the production process. $^{35}$ This review summarizes current research in therapeutic delivery via 
extracellular vesicles and thoroughly examines methods for overcoming challenges associated with EVs in therapeutic delivery.

\section{Extracellular vesicles (EVs)}

Recent studies have shown promise for extracellular vesicles in the field of therapeutic delivery. ${ }^{30,22,36,37}$ This stems from the unique factors associated with EVs including their inherent biocompatibility and targeting potential. As an introduction to EVs, this section will review their biogenesis and intrinsic utility. A discussion of the challenges associated with EVs in therapeutic delivery follows.

\subsection{Formation and composition}

Vesiculation is a key factor in numerous biological processes, and naturally occurring EVs range dramatically in size and function. ${ }^{36,38,39}$ In some cases, EVs were named based on the cells from which they were derived; this has led to confusion in the nomenclature and the development of terminology including dexosomes, epididimosomes, argosomes, prostasomes, etc. ${ }^{40}$ However, for clarity and the purpose of this review, EVs will be loosely grouped into three core categories shown in Figure 2: exosomes, microvesicles, and apoptotic bodies.

Exosomes, ranging from 30 to $100 \mathrm{~nm}$ in diameter, are produced from inward budding of endosomal compartments called multivesicular bodies (MVBs). ${ }^{21}$ In some cases, MVBs fuse with lysosomes and are degraded; however, MVBs may alternatively fuse with the plasma membrane and release their contents into the extracellular space. ${ }^{41}$ Originally, exosomes were believed to be alternatives to lysosomes as they 


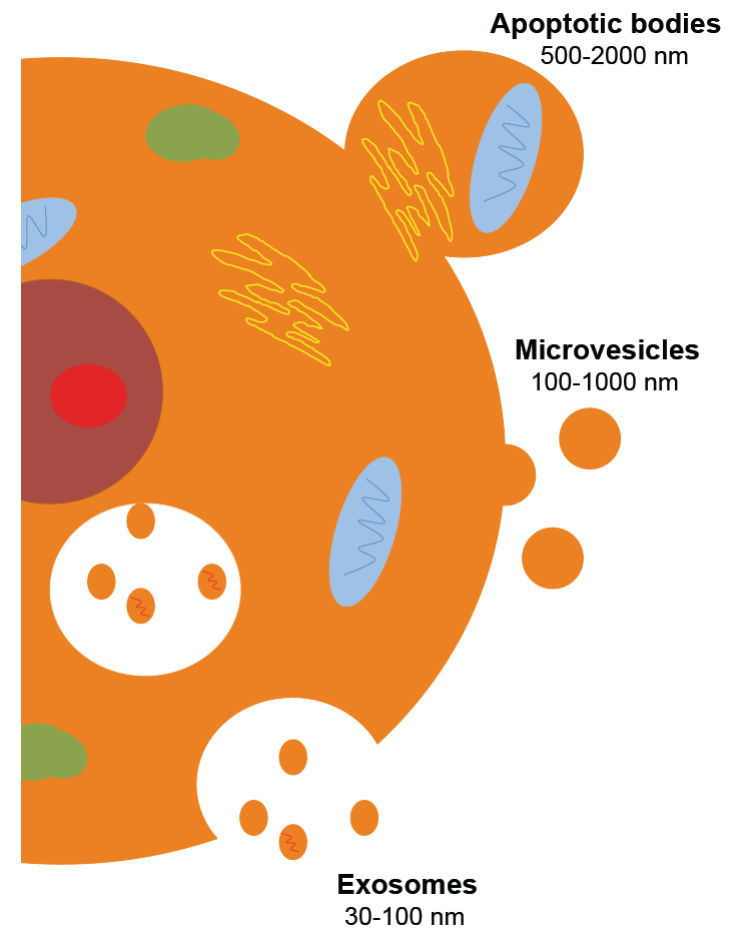

Figure 2. The categories of extracellular vesicles. ${ }^{36,39,38}$ Apoptotic bodies are only produced during cell death, while microvesicles and exosomes are released throughout all stages of the cell cycle. Exosomes and microvesicles are within the appropriate size-range for effective therapeutic delivery. were known to excrete obsolete proteins from the cell. It is now apparent that exosomes have a variety of functions and are capable of transporting mRNA and miRNA $^{22}$ between cells to aid in angiogenesis ${ }^{42}$, proliferation and survival. ${ }^{43}$

Slightly larger than exosomes, microvesicles ( 100-1000 nm) bud directly from the plasma membrane, transporting cargo away from the cell. Although it has been shown that specific molecules are enriched in microvesicles ${ }^{44}$, the mechanism by which this occurs is not fully understood. In general, cells release microvesicles at a relatively slow rate; conversely, cancer cells produce these EVs at a rapid rate ${ }^{45}$ which is hypothesized to aid in their proliferation and survival.

The largest of the EVs, apoptotic bodies are micron-sized carriers of organelles and form as a cell begins to degrade during apoptosis. ${ }^{36}$ The relatively large size range of apoptotic bodies excludes them from being considered as potential carriers. For the purpose of this review, the focus will be kept on exosomes and microvesicles as potential therapeutic carriers. 


\subsection{Biological function}

EVs have a wide-array of intrinsic functions. They participate in tissue repair and immune surveillance ${ }^{46-51}$, transport transcription factors and mRNAs ${ }^{49,52-55}$, and activate

cell surface receptors with protein and lipid ligands. ${ }^{47,56}$ All in all, they possess the ability to control cellular and biological function through multiple dynamic mechanisms.

More importantly, studies have shown that EVs have the potential to be immunostimulatory or immunosuppressive.$^{57}$ Therefore, EV populations can be selected as delivery vehicles with the goal of avoiding immunogenic response. Since exosomes have been shown to express MHC class I and class II molecules from their cell of origin $^{21}$, utilizing exosomes derived from a patient's own cells should be sufficient to avoid immunogenic response.

Clearly the intrinsic functions of EVs must be accounted for when designing therapeutic carriers. A refined selection of EVs will result in an effective therapeutic carrier $^{22}$ that has the ability to target a specific population of cells ${ }^{58}$ for delivery of desired cargo without inducing immunogenic response..$^{59}$

\section{Isolation and purification}

Improving methods for isolation and purification of EVs is a significant challenge. ${ }^{60,61}$ This section summarizes conventional strategies of isolation and purification as well as emerging devices for improving EV isolation efficiency (Figure 3).

\subsection{Conventional strategies}




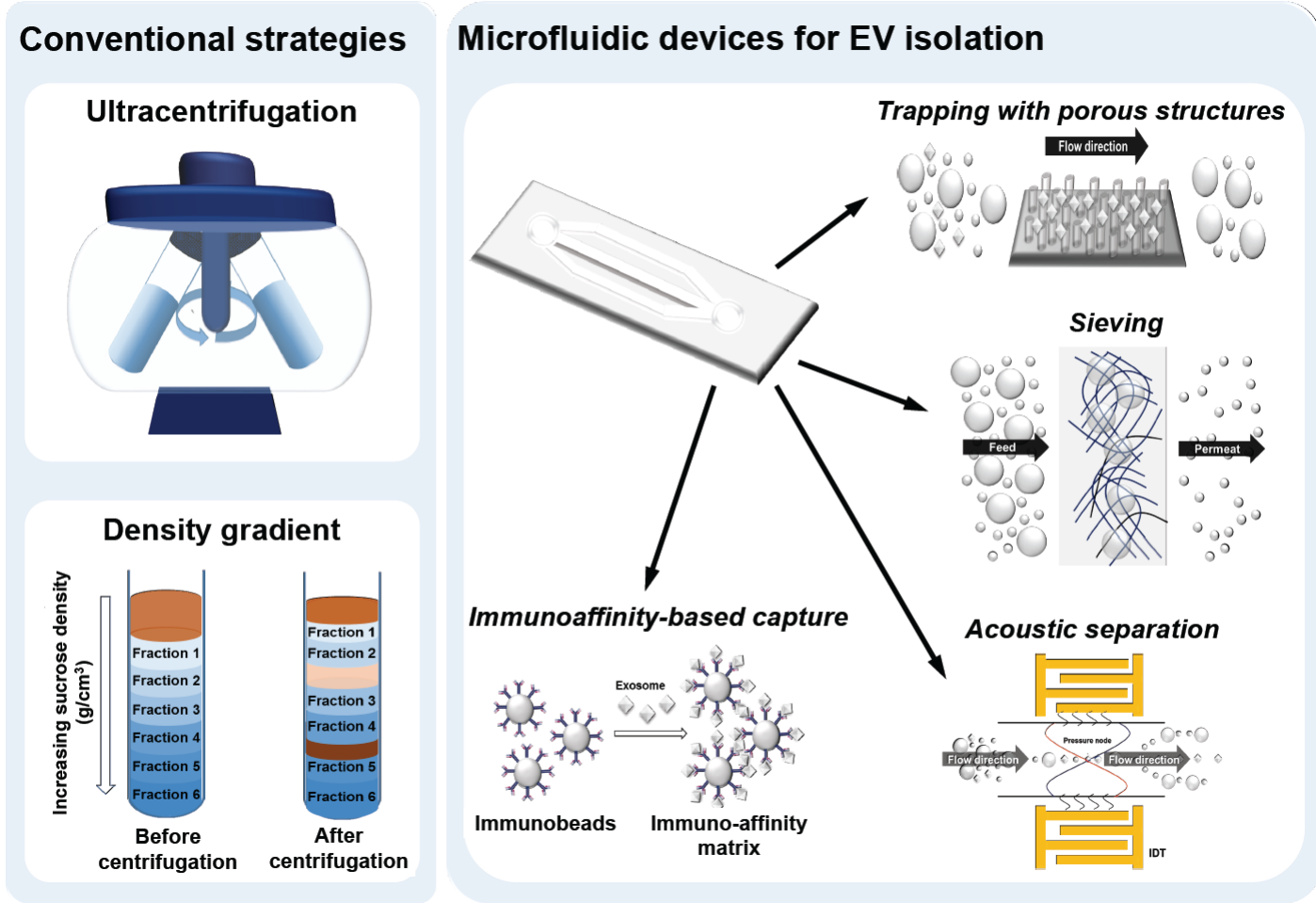

Figure 3. Strategies for extracellular vesicle isolation. ${ }^{69,72,74,76-77}$ Ultracentrifugation and density gradient fractionation are most commonly used in EV isolation. However, a variety of emerging devices are enabling faster and/or more specific isolation.

Conventional strategies for EV isolation are mostly based on size and buoyant density. The most common strategy used for isolating EVs is ultracentrifugation, a method that includes performing a sequence of centrifugation steps reaching speeds often greater than $100,000 \mathrm{~g}$. In the first step, centrifugation at $1000 \mathrm{~g}$ removes cells including dead cells and relatively large cell debris. Next, ultracentrifugation steps reaching speeds near $100,000 \mathrm{~g}$ concentrate the EVs. ${ }^{62,63}$ Although widely used for EV isolation, centrifugation is time consuming ( $>4$ hours for standard protocols), yields poor EV recovery $(5 \sim 25 \%)^{64,65}$, has low specificity (co-purification with non EV debris), and requires skilled technicians and expensive equipment. ${ }^{66}$ Density-gradient separation techniques, such as adding a sucrose gradient centrifugation step, improve the purity 
and the recovery rate of extracted EVs compared to differential centrifugation. ${ }^{62}$ While density-gradient separation strategies can lead to higher purity and improved recovery rate ${ }^{62,67}$ they are less time efficient due to complicated sample processing. Also, these techniques require the same ultracentrifugation equipment and may be impractical for many clinical applications. ${ }^{62,68}$

\subsection{Emerging devices for EV isolation}

In the last few years, new devices have emerged to scale microfluidics to the nanoscale for EV isolation. These devices, summarized in Table 1 along with conventional methods, have great potential to improve EV isolation by increasing the purity of isolated EV samples and reducing isolation time and reagent volume. However, most strategies for isolating EVs using nanoscale devices have challenges such as offchip steps for sample preparation including reagent mixing or plasma extraction. ${ }^{69,70}$

Table 1. Comparison of conventional strategies and microfluidic devices for isolation of EVs. ${ }^{69-77}$

\begin{tabular}{ccccccc}
\hline & \multicolumn{3}{c}{ Conventional strategies } & \multicolumn{3}{c}{ Microfluidic devices } \\
\cline { 2 - 7 } & $\begin{array}{c}\text { Ultracentifug } \\
\text { ation }\end{array}$ & $\begin{array}{c}\text { Density } \\
\text { gradient }\end{array}$ & $\begin{array}{c}\text { Immunoaffini } \\
\text { ty-based } \\
\text { capture }\end{array}$ & Sieving & $\begin{array}{c}\text { Trapping } \\
\text { with porous } \\
\text { structures }\end{array}$ & $\begin{array}{c}\text { Acoustic } \\
\text { separation }\end{array}$ \\
\hline Time & $>4 \mathrm{~h}$ & $>4 \mathrm{~h}$ & $\sim 1 \mathrm{~h}$ & $\sim 2 \mathrm{~h}$ & $\sim 10 \mathrm{~min}$ & $<1 \mathrm{~h}$ \\
\hline Recovery & $5-25 \%$ & $30-65 \%$ & $25 \sim 80 \%$ & $<25 \%$ & $\sim 60 \%$ & $>80 \%$ \\
\hline Purity & Poor & Fair & Good & Fair & Fair & Fair \\
\hline
\end{tabular}

\subsubsection{Immunoaffinity-based capture}

Unlike conventional strategies that isolate and purify EVs based on their size and buoyant density, immunoaffinity-based capture strategies are based on the highly 
specific interaction of a target with its antibody associated ligand. The highly selective binding of antibodies to specific targets offers advantages compared to conventional separation techniques including reduced isolation times, preservation of protein activity by gentle elution conditions and increased purification efficiency. ${ }^{70,71}$ By performing immunoaffinity based isolation using a microfluidic device modified with biotinylated anti-CD63 (a common exosomal marker), Chen et al. ${ }^{72}$ and Kanwar et al. ${ }^{69}$ demonstrated fast $(\sim 1 \mathrm{~h})$ and specific isolation of EVs from cell culture media and serum samples. He et al. ${ }^{73}$ reported a cascading microfluidic device for the purpose of combining specific immunoisolation with targeted protein analysis of circulating exosomes from patient's plasma. The on-chip isolation with antibody-labeled magnetic beads (immunomagnetic method) allows for capture and enrichment of EVs due to the large surface area of the beads. This isolation strategy takes less than 1.5 hours and requires plasma sample volumes as low as $30 \mu \mathrm{L}$. Compared to other isolation methods

that rely on physical properties, immunoaffinity-based capture strategies are able to attain higher purity of isolated EVs. However, they also result in a significantly reduced yield of vesicles and damage to captured vesicles. All in all, immunoaffinity-based isolation strategies coupled with a downstream analysis technique are a potent method of characterization that can be applied in clinical practice.

\subsubsection{Sieving}

Using in situ prepared nanoporous membranes called porous polymer monoliths (PPM), Davies et al. ${ }^{74}$ developed a microfluidic filtration system for the isolation of EVs from whole blood samples. Employing DC electrophoresis as an alternative driving force 
to propel EVs across the filter, electrophoresis-driven filtration enhances the isolation purity of EVs compared to pressure-driven filtration because cells and cell-derived EVs are more sensitive to electric fields than proteins and other molecules due to their greater negative surface charge. ${ }^{75}$ Whereas this technique has advantages such as relatively short processing time and high purity of isolated exosomes, it results in low recovery of isolated $\mathrm{EVs}$.

\subsubsection{Trapping with porous structures}

Wang et al. ${ }^{76}$ developed a microfluidic device using a porous silicon nanowire-onmicropillar structure consisting of hierarchical ciliated micropillars. They demonstrate selectively trapping EV-like lipid vesicles within interstitial sites between the nanowires

during filtration of biofluids. According to Wang et al. ${ }^{76}$, this technique allows for the high purity recovery of EV-like lipid vesicles by dissolving the silicon nanowires in PBS buffer.

The procedure of trapping EV-like lipid vesicles through nanowire-on-micropillar structures is fast $(\sim 10 \mathrm{~min})$ and requires a small sample volume $(\sim 100 \mu \mathrm{L})$ due to the microscale channels. Although advanced techniques can reduce the chances of clogging by increasing the number of micropillars, such a system would require a recovery procedure including dissolving the silicon nanowires in PBS buffer overnight.

\subsubsection{Acoustic separation}

Lee et al. ${ }^{77}$ reported on an acoustic-based microfluidic system for continuous and contact-free filtration of EVs according to their size and density. They optimized the system's IDT electrode (ultrasound transducer) and underlying electronics to exert 
efficient acoustic force on EVs. Larger EVs migrate faster across the microfluidic channel than smaller ones due to acoustic force. The system achieved high separation yields (>90\%) of EVs from biological samples and was able to control in situ "filter sizecutoff". In addition, this device achieved $>80 \%$ recovery of exosomes from cell culture media as well as microvesicles in stored red blood cell products. By adjusting the acoustic field or flow velocity for different size-cutoffs, this acoustic-based microfluidic system can be applied to differentiate multiple types of EVs according to their size profile.

\section{Characterization}

Understanding the specific traits of individual samples of EVs is necessary in order to take full advantage of their potential as therapeutic carriers. The challenge associated with characterization stems from the fact that samples of EVs vary greatly in intravesicular content and membrane composition. Literature over the past decade has begun to characterize EVs; however, future work defining intrinsic contents, surface markers, and biological functions will be necessary before EVs can be approved as therapeutic carriers in the clinic.

In this section, we discuss commonly used methods for characterizing EVs. To overcome the challenges associated with characterizing nano-sized EVs without using specific markers, combination methods that include both optical and non-optical techniques are often utilized.

\subsection{Electron microscopy}


Electron microscopy (EM) is commonly used to provide information on the size and structure of EVs. Concentrated EVs are fixed on grids or stages, stained with dye, and visualized by EM (e.g., TEM and SEM). ${ }^{78,79}$ Electron microscopy images provide information on size, morphology and, when labeled, the presence of specific biomarkers. However, the concentration of EVs cannot be measured using this technique. Additionally, the application of EM requires complex and extensive processing including dehydration, fixation, and metallization.

\subsection{Dynamic light scattering (DLS) and nanoparticle tracking analysis (NTA)}

New approaches based on light scattering such as dynamic light scattering (DLS) and nanoparticle tracking analysis (NTA) have emerged for the detection of single EVs. ${ }^{80-82}$ DLS is commonly used to determine the size and distribution of EVs by measuring the dynamic changes in fluctuations from the light scattering due to Brownian motion. The diffusion rate of EVs depends on the temperature; hence, DLS measurements of EVs require careful sample preparation. Furthermore, DLS is not suitable for heterogeneous mixtures of EVs because DLS accuracy swiftly declines in the presence of large particles. NTA measures concentration and size distribution of EVs through combining dark-field microscopy and software that tracks the motion of EVs; it then calculates the diameter of the EVs based on the Stokes-Einstein equation. NTA has also been used to demonstrate profiling of fluorescently labeled EVs. ${ }^{83}$ Using NTA, vesicles with similar size and similar Brownian motion cannot be distinguished and, hence, isolation and purification steps are needed. Currently, NTA is the most widely used technique in measuring the size distribution and concentration of EVs. 


\subsection{Flow cytometry}

Flow cytometry, a laser-based technology, may be used to characterize EVs in fluids providing important information about their physical and chemical characteristics. ${ }^{84}$ In general, flow cytometry can detect vesicles above $300 \mathrm{~nm}$ in diameter. ${ }^{85}$ Weak signal makes analyzing EVs via flow cytometry challenging. To overcome this limitation, EVs are conjugated on large beads and labeled with a fluorophore. Flow cytometry is a powerful tool for analysis of EVs and can be used to analyze individual exosomes and measure multiple surface markers per exosome.

\subsection{Surface plasmon resonance (SPR)}

Surface plasmon resonance (SPR)-based nanosensors are being rapidly developed for the study of ligand binding interactions with a small number of biomolecules. Because SPR is label-free and allows one to measure real time quantitative binding affinities, SPR-based nanosensors are suited for detection of EVs. ${ }^{85,86} \mathrm{Im}$ et al. ${ }^{87}$ developed a nano-plasmonic sensor termed nano-plasmonic exosome (nPLEX) to detect and profile exosomes. The nPLEX is composed of periodic nanohole arrays, wherein target-specific ligands capture exosomes. The diameter and periodicity of nanoholes were optimized to match the mean diameter of exosomes. When exosomes bind to a nanohole array, binding induces a spectral shift that is correlated to the mass of the bound exosome. This system is integrated with miniaturized optics consisting of a laser diode and image sensor to monitor changes in the transmitted light intensities for parallel measurements. 


\subsection{Membrane composition analysis}

Western blotting is one of the most common techniques for identifying specific proteins in EV membranes. For a broader approach, proteomic analysis with SDSPAGE or HPLC followed by mass spectrometry may be used. ${ }^{88}$ Conde-Vancells et al. ${ }^{89}$ comprehensively characterized the protein composition of hepatocyte-secreted exosomes by both methods. In addition to proteomics, EVs may be analyzed by lipidomics. Llorente et al. ${ }^{90}$ used extensive lipid analysis to find differences in the lipid composition of cells and their exosomes. Several databases, such as Vesiclepedia, summarize the latest research on protein and lipid content associated with EVs. ${ }^{91}$ Characterization of membrane composition is important for both taking advantage of EV potential for therapeutic delivery and for quality control. ${ }^{92,93}$

\section{Quality control}

Before EVs can be seriously considered for clinical trials, quality control parameters must be met. Since the field is in its infancy, these parameters are still being debated. However, they will most certainly include standards describing the contents and composition of therapeutic vesicles. This section summarizes current findings regarding the intravesicular contents and membrane composition of EVs.

\subsection{Intravesicular contents}

Studies have shown that both exosomes and microvesicles contain transcription factors and RNAs from their parent cells. ${ }^{52,53,94}$ However, their content is not always 
representative of that of the cells from which they were derived. ${ }^{22}$ EVs serve as a means to transport intracellular content between cells, and may be enriched in certain proteins and RNAs by a means that is not fully understood.

Interest in cancer associated EVs has led to a surge of research in the field, some of which has indicated that EVs from malignant cells contribute to metastasis. Skog et al. ${ }^{95}$ showed that glioblastoma microvesicles carrying RNA and angiogenic proteins such as angiogenin, VEGF and TIMP-2 aid in metastatis and angiogenesis. Contrastingly, BajKryzworzeka et al. ${ }^{55}$ determined that tumor cell-derived microvesicles transporting vascular endothelial growth factor, hepatocyte growth factor and interleukin-8 had antiapoptotic effects on monocytes; this indicates that cancer-derived vesicles actually aid in macrophage survival. Further research is expected to shed new light on the role of EVs in cancer progression. However, these studies indicate that the intrinsic biological functions of EVs must be accounted for when designing therapeutic carriers.

\subsection{Membrane composition}

Known to express certain surface markers, EVs also possess biological function associated with their membrane composition. In general, exosomes have been characterized by enriched levels of transmembrane proteins, such as CD9 and CD63, as well as integral membrane proteins, such as Flotillin-1. ${ }^{94,96}$ Additionally, exosomes have surface molecules that are specific to the cell type and activation state from which they were derived. For example, cancer exosomes express NKG2D ligand, which binds $\mathrm{T}$ and $\mathrm{B}$ cells in a form of immune evasion. ${ }^{58}$ Although the composition of exosomal surface markers is dependent on the parent cell, it is often quite different from the 
composition of the plasma membrane. ${ }^{34}$ Contrastingly, microvesicles maintain the surface composition of the plasma membrane because they are formed through budding of the plasma membrane. ${ }^{97}$

The most intriguing aspects of using EVs for therapeutic delivery are the possibilities of innate targeting, immune activation and immune evasion. The literature has described exosomes that specifically target cell types depending on their source ${ }^{28}$, but further work is necessary to explicate the mechanism by which these interactions occur. Obregon et al. ${ }^{77}$ demonstrated EV immune activation in 2006. Lipopolysaccharide activated dendritic cell-derived microvesicles were able to prime $\mathrm{T}$ cells via transfer to resting dendritic cells. ${ }^{98,99}$ Shortly after, EVs derived from cells with MHC markers were shown to express MHC class I and class II proteins. ${ }^{100}$ MHC molecules enable EVs to transport material in the extracellular space without stimulating an immune response.

If EVs are to make progress as therapeutic delivery agents, future work should provide insight into the intrinsic functions of EVs and how these functions are related to their composition. With sufficient understanding of their biological functions, EVs can be harnessed to target specific cell lines, activate the immune system to an antigen, and/or navigate the extracellular space without initiating immune response.

\section{Mass production}

Following thorough characterization and quality control, optimization of EV production is the next major challenge in the field. Currently, billions of cells must be cultured in vitro in order to harvest a few micrograms of EVs; this process of production 
is inefficient and limits the potential of EV technology for personalized therapeutic delivery. ${ }^{32}$ To improve vesicle production efficiency, several potential methods for increasing the overall EV yield have been reported. This review will focus on three key methodologies: intracellular calcium levels, external stress, and cytoskeletal fixation.

\subsection{Intracellular calcium levels}

There have been several studies demonstrating that an increase in intracellular calcium levels leads to extracellular vesicle formation. ${ }^{101-105}$ Interestingly, this phenomenon has been reported for both exosomes and microvesicles despite the differences in their biogenesis. For example, in 2003, Savina et al. ${ }^{101}$ reported an increase in exosome release when intracellular calcium levels were elevated via monensin-stimulation. This was due to a heightened propensity of multivesicular bodies to fuse with the plasma membrane at high $\mathrm{Ca}^{2+}$ concentrations. Calcium-dependence also comes into play during microvesicle formation, and Miyoshi et al. ${ }^{105}$ demonstrated that increases in $\mathrm{Ca}^{2+}$ concentration lead to degradation of cytoskeletal proteins and increased membrane blebbing.

\subsection{External stress}

External stress such as thermal stress $^{58}$, hypoxia $^{106}$, radiation ${ }^{107}$ and microenvironmental $\mathrm{pH}^{108}$ has been shown to increase $\mathrm{EV}$

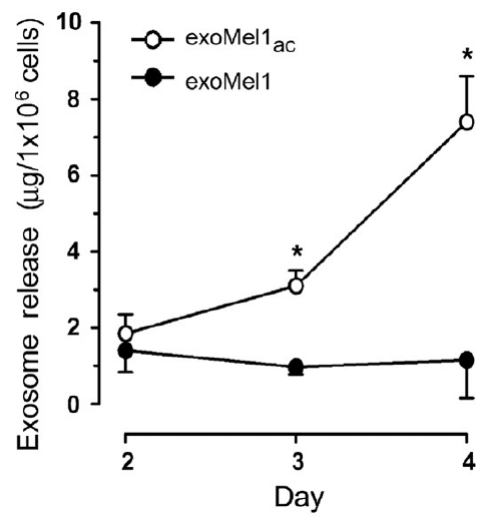

Figure 4. Stimulated exosome secretion in acidic conditions. Mel1 cells cultured at pH 6 (light marker) release more exosomes than those cultured at $\mathrm{pH} 7.4$ (dark marker). ${ }^{108}$ Figure is reprinted with permission from the American Society for Biochemistry and Molecular Biology. 
production. The majority of current studies have focused on EV release from malignant cells as a means of tumor-promotion. In 2009, Wysoczynski and Ratajzczak ${ }^{107}$ showed $^{2}$ that increased EV production from lung cancer cells exposed to hypoxia and radiation led to induction of pro-angiopoietic factors in stromal cells. That same year, Parolini et al. ${ }^{108}$ demonstrated that a key protein involved in melanoma progression is delivered via cancer-derived exosomes produced under acidic conditions; as shown in Figure 4, exosome production is stimulated at $\mathrm{pH} 6$ in comparison to the control at $\mathrm{pH} 7$.

EVs produced via stress also have the ability to promote immunosuppression; when exposed to thermal and oxidative stress, leukemia and lymphoma cells produce specific ligand-bearing exosomes contributing to immune evasion. ${ }^{58}$ Although stress certainly causes increased EV production, the composition of EVs produced under such conditions is markedly different. ${ }^{109}$ Future studies should aim to characterize changes in biological functions of EVs resulting from stress as a means to evaluate the potential of this method of mass production.

\subsection{Cytoskeletal fixation}

In 2012, Sezgin et al. ${ }^{92}$ published a protocol for producing and isolating microvesicles using sulfhydryl-blocking reagents ${ }^{110-112}$ to

stimulate vesicle

production. Figure $\mathbf{5}$
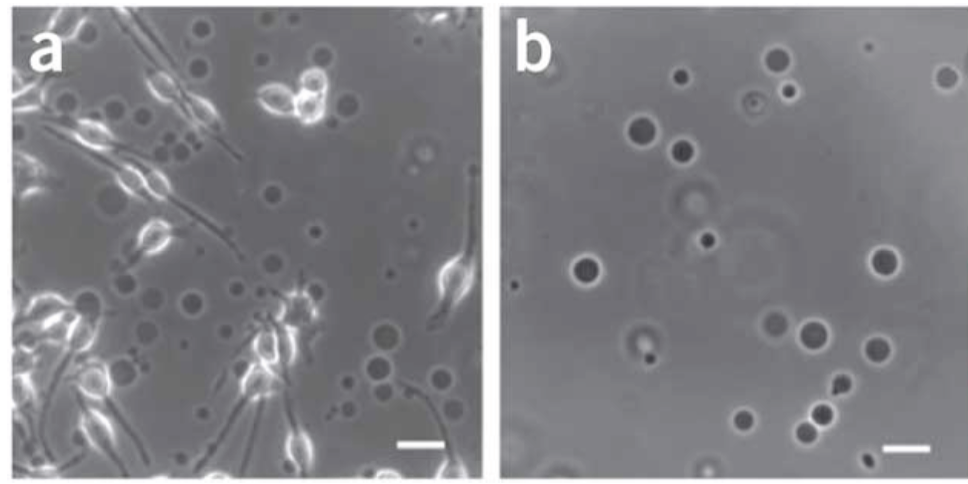

Figure 5. Giant plasma membrane vesicles produced from adherent cells (a) and isolated (b) via differential centrifugation. Vesicles were produced by incubating HeLa cells with paraformaldehyde and dithiothreitol to stimulate blebbing. ${ }^{26}$ Scale bar $=20 \mu \mathrm{m}$. Figure is reprinted with permission from the Nature Publishing Group. 
shows these microvesicles prior to and following isolation and purification. ${ }^{26}$ Blebbing, the protrusion and retraction of portions of the plasma membrane, is a result of changes in hydrostatic pressure, which are counteracted by cytoskeletal mechanisms. ${ }^{113}$ As diagrammed in Figure 6, the opposing forces between the hydrostatic pressure of the cytoplasm and the retraction of the actin filaments determines whether a vesicle is released or the bleb retracts ${ }^{114}$ and so blebbing relies heavily on actin and myosin function. ${ }^{115}$ Therefore, impeding cytoskeletal function via incubation with sulfhydrylblocking reagents is a method of inducing rapid EV formation. Although the focus of their work was to model membrane rafts, their method of producing vesicles is relevant and important to the field of vesicular delivery.

In 2013, Zeng et al. ${ }^{27}$ published an extensive article correlating blebbing rate and average bleb size with percentage of reagent in solution. Concentration not only affects actin-myosin function but also correlates with media osmolality; this confirms the

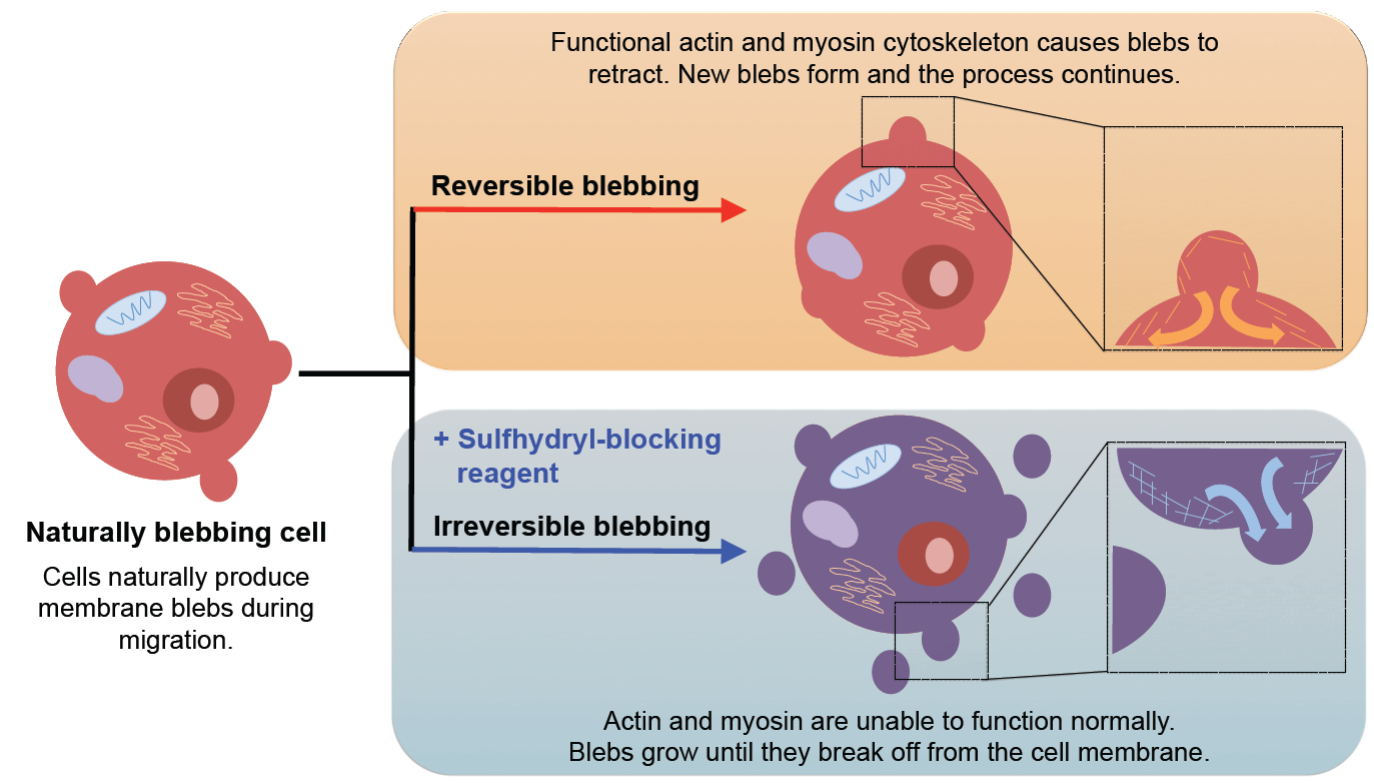

Figure 6. Mechanism of EV production via exposure to sulfhydryl blocking reagents. ${ }^{26 \text {, }}$ ${ }^{110-115}$ A functional cytoskeleton retracts blebs that form due to hydrostatic pressure differences. When actin/myosin function is inhibited, blebbing leads to the release of vesicles. 
importance of hydrostatic pressure and actin-myosin function on blebbing. In addition to chemical reagents, biological actin/myosin inhibitors and chemical crosslinking agents have been used to induce vesiculation by hindering actin functionality and halting bleb retraction. $^{26,113}$

Considering all methods of inducing EV formation, cytoskeletal inhibition via sulfhydryl-blocking reagents is highly advantageous because of its extremely rapid rate of EV production. While calcium- and stress-induced EV production requires between 12 hours and several days to achieve significantly improved yield ${ }^{101,108}$, this can be done in just one hour with sulfhydryl-blocking reagents ${ }^{26}$. Additionally, microvesicles generated in this way should, in theory, be relatively simple to characterize and modify since they should have the same membrane composition and intravesicular cytosol components as their parent cells. Further investigation will be necessary for determining whether EVs formed from sulfhydryl-blocking of the cytoskeleton maintain the same biological activity as naturally occurring EVs.

\section{Therapeutic loading}

Effective loading of the therapeutic of interest in one major challenge associated with EV therapeutic delivery. Synthetic carriers, such as liposomes, can be loaded during the synthesis process. However, EVs are isolated directly from cells and therefore must undergo therapeutic loading post formation. Some have attempted to overcome the challenge of loading EVs by instead loading the cells from which they are to be derived.

\subsection{Loading of EVs via cell of origin}


EVs naturally carry RNAs such as miRNA throughout the bloodstream. ${ }^{116}$ Therefore, RNA-containing EVs may be obtained without further loading steps. However, efficient loading of EVs with RNA of interest can be more effectively achieved by first loading the parent cell. In 2011, Akao et al. ${ }^{117}$ demonstrated that macrophages transfected with miR-143 secrete vesicles containing the miRNA at an entrapment efficiency of $\sim 0.20$ $0.25 \%$. Small molecules have also been loaded into EVs this way. Pascucci et al. ${ }^{29}$ produced microvesicles containing Paclitaxel from mesenchymal stromal cells loaded with the drug.

\subsection{Direct EV loading}

Direct EV loading is much more common in the literature and involves loading EVs after isolation from the parent cells. In the following subsections, we describe a broad range of passive and active loading strategies. Although these strategies require additional purification processes in comparison to loading EVs via their parent cells, they often produce more efficient loading outcomes.

\subsubsection{Passive loading}

Passive loading is the simplest method of introducing a therapeutic of interest into EVs. The strategy involves incubating the isolated EVs with the therapeutic and then purifying the EVs post-loading. Sun et al. ${ }^{28}$ demonstrated passive loading of exosomes incubated with curcumin. Incubation of exosomes with curcumin for 5 minutes produced a loading rate of $2.9 \mathrm{~g}$ curcumin per $1 \mathrm{~g}$ exosomes and allowed for delayed release in vivo. Recently, Saari et al. ${ }^{118}$ described passive loading of prostate cancer cell-derived 
exosomes with Paclitaxel; $9.2 \%$ of the drug was loaded after a one-hour incubation at room temperature.

\subsubsection{Active loading}

Active loading refers to strategies that enable more efficient penetration of therapeutic through the lipid bilayer than exclusive incubation. Electroporation, which involves increasing the permeability of the EV membrane by applying electric pulses, is perhaps the most common active loading strategy applied to EVs. Hood et al. ${ }^{119}$ applied single-pulse electroporation to exosomes to load RNA and demonstrated a significant loading enhancement compared to passive loading. Wahlgren et al. ${ }^{54}$ optimized electroporation for loading RNA into exosomes. The reported the optimized conditions as $150 \mathrm{~V} / 100 \mu \mathrm{F}$.

Recently, Haney et al. ${ }^{120}$ compared several other methods of active loading: permeabilization with saponin, freeze-thaw cycles, sonication, and extrusion. Sonication of exosomes in the presence of the therapeutic, catalase, proved to be the best formulation with the highest loading efficiency of $\sim 200 \mu \mathrm{g}$ catalase per mg exosomes and slowest release. To preserve the exosome structure, sonication was completed at $20 \%$ power with brief pulses of 4 seconds each.

\section{Potential applications of EVs in therapeutic delivery}

Despite the challenges associated with EVs, recent publications have demonstrated their ability as therapeutic carriers and vaccines. ${ }^{121-124}$ EVs have great potential as therapeutic carriers because they can be engineered to meet specific needs. Careful 
choice of parent cells from which to derive EVs allows for selection of biological function of the vesicles. As for therapeutic function, EVs can deliver intrinsic cargo or be engineered to carry exogenously loaded cargo. Recent work by Hung and Leonard ${ }^{125}$ provides a method for stabilizing proteins on the surface of EVs for enhanced targeting. Additionally, protein expression on EVs surface may be engineered when necessary. ${ }^{126,127}$ Figure 7 sums up the four categories of engineered EVs: those with surface modifications, cargo loading, both or neither. The following sections describe current progress in EVs for therapeutic delivery.

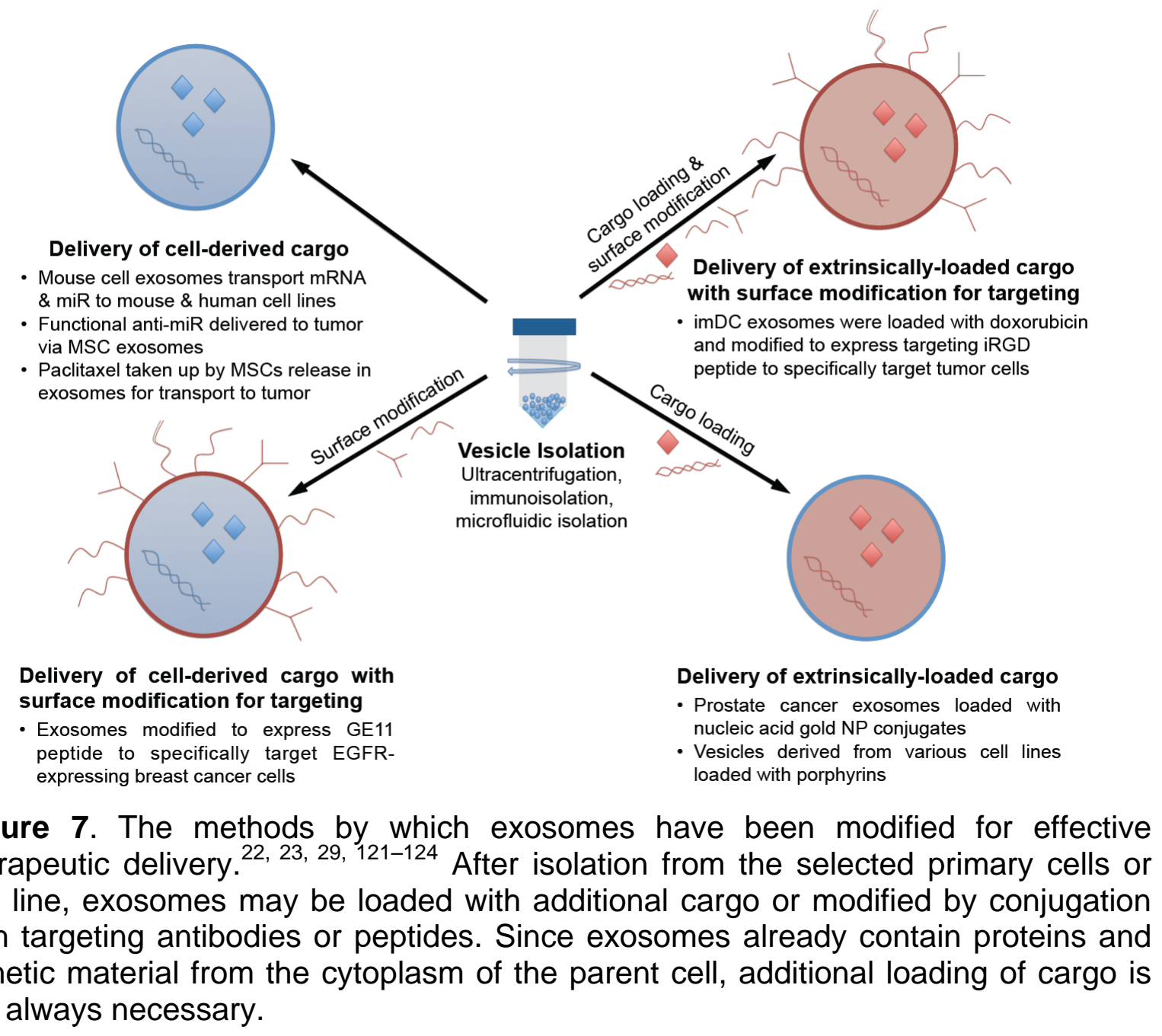




\subsection{Gene and protein delivery}

In 2007, Valadi et al. ${ }^{22}$ established that exosomes were involved in the exchange of mRNAs and miRNAs between cells. Additionally, the mRNA and miRNA was functional in its new location even if the target cell was of another species. From this starting point, various miRNAs and other forms of RNA including siRNA were shown to be transported by EVs. ${ }^{117,128-130}$ The first demonstration that exosomes could be used as carriers to deliver exogenous siRNA came in 2011. Alvarez-Erviti et al..$^{30}$ loaded dendritic cell exosomes with siRNA via electroporation and demonstrated knockdown of BACE1, an Alzheimer's target, in the brains of mice. To improve RNA loading into EVs, Hung and Leonard $^{131}$ developed an EV loading protein fused with RNA.

Recently, Shimoda et al. ${ }^{132}$ demonstrated that exosomes derived from CagAexpressing cells contain virulence factor CagA. Furthermore, the exosomes were capable of delivering the CagA to gastric epithelial cells. This study was among the first promising indications that EVs can be used to deliver proteins to target cells. Aspe et al. ${ }^{133}$ also demonstrated protein delivery via exosomes; melanoma-derived exosomes were able to deliver Survivin to pancreatic carcinoma cells.

\subsection{Drug delivery}

Exosomes have been used for the delivery of exogenous pharmaceutical agents. The first demonstration of such delivery was in 2010 when Sun et al. ${ }^{28}$ showed that EL4-derived exosomes complexed with curcumin exhibited improved circulation and targeting in comparison to the free drug. Recently, Tian et al. ${ }^{23}$ used exosomes engineered to express iRGD peptide to improve doxorubicin delivery in vivo. When not 
possible to obtain sufficient quantities of EVs, exosome-mimetic vesicles have also been utilized for doxorubicin delivery. ${ }^{134}$

Although EVs derived can be derived from many sources including bovine milk ${ }^{135}$, most studies focus on utilizing EVs derived from the target cells themselves. In 2015, Saari et al. ${ }^{118}$ demonstrated that prostate-cancer EVs efficiently delivered Paclitaxel to prostate cancer cells in vitro. In the same year, Yang et al. ${ }^{10}$ showed that exosomes isolated from brain culture media could transport drugs across the blood-brain barrier.

Despite these advances, a limiting factor in such drug delivery is the efficiency of EV loading. Pascucci et al. ${ }^{29}$ overcame this issue by exposing cells directly to the drug of interest and then deriving drug loaded exosomes from those cells. This method was efficient in delivering paclitaxel and achieving an antiproliferative effect against human pancreatic adenocarcinoma cells in vitro.

\subsection{Immunotherapy}

EVs have great promise for immunotherapy since they can carry antigens. Bartolini et al. ${ }^{136}$ demonstrated that outer membrane vesicles from bacteria expressing Chlamydia muridarum antigen induced antibodies capable of neutralizing chlamydial infection in vitro. In the same year, Cheng et al. ${ }^{137}$ used mycobacterial antigens in purified macrophage exosomes to prime antigen-specific T-cell response in mice. In a study by Mahaweni et al. ${ }^{138}$, EVs play an indirect role. Tumor-derived exosomes were used to deliver antigens to dendritic cells, which were subsequently used for immunotherapy. 
Like their parent cells, dendritic cells exosomes (Dex) have become the focus on many studies due to their ability to directly mediate immune response. ${ }^{139}$ Colino et al. ${ }^{140}$ demonstrated induction of Ag-specific immunity in mice using Dex derived from diphtheria toxoid-pulsed dendritic cells. In 2011, del Cacho et al. ${ }^{141}$ compared antigenloaded dendritic cell vaccination to Dex vaccination against Eimeria tenella. Both methods were effective in achieving Ag-specific immunity in chickens.

\section{Conclusions}

Utilizing vesicles derived from a patient's own cells offers a means of biocompatible delivery beyond the scope of any synthetic carrier. In the last decade, significant progress has been made towards harnessing EVs for therapeutic delivery. EVs have been used to delivery genetic material, protein and small molecules to target cells in vitro and in vivo. Nevertheless, improvement of characterization, quality control and loading protocols are still needed. Most importantly, scale-up EV production must be optimized in order for EV therapy to move to large clinical studies. Since effective production will be key to this emerging field in therapeutic delivery, we recommend two areas of focus for future studies in EV mass production: 1) developing methods for mass production of EVs from cell culture, and 2) comprehensive characterization of EVs derived via such methods to ensure that quality control can be attained. The opportunity to development personalized, natural therapeutic carriers has generated great interest over the last decade, and we expect that the field will continue to grow and conquer the challenges associated with harnessing EV therapeutics in the coming years. 


\section{Acknowledgements}

DI was supported by the National Science Foundation Graduate Research Fellowship (DGE-1321846). This work is also supported by the National Research Foundation of Korea (NRF) (2016R1A2A1A05005465/2010-0027955) sponsored by the Ministry of

Science, ICT, and Future Planning (MSIP) of Korea. Y.J.K. was supported by the Brain Pool Program through the Korean Federation of Science and Technology Societies funded by MSIP.

\section{References}

1. Ganta S, Devalapally H, Shahiwala A, Amiji M. A review of stimuli-responsive nanocarriers for drug and gene delivery. J Control Release. 2008;126(3):187-204. doi:10.1016/j.jconrel.2007.12.017.

2. Hillaireau H, Couvreur P. Nanocarriers' entry into the cell: Relevance to drug delivery. Cell Mol Life Sci. 2009;66(17):2873-2896. doi:10.1007/s00018-0090053-z.

3. Kesharwani P, Gajbhiye V, Jain NK. A review of nanocarriers for the delivery of small interfering RNA. Biomaterials. 2012;33(29):7138-7150. doi:10.1016/j.biomaterials.2012.06.068.

4. Petros R a, DeSimone JM. Strategies in the design of nanoparticles for therapeutic applications. Nat Rev Drug Discov. 2010;9(8):615-627. doi:10.1038/nrd2591.

5. Allen TM, Cullis PR. Drug delivery systems: entering the mainstream. Science. 2004;303(5665):1818-1822. doi:10.1126/science.1095833. 
6. El-Aneed A. An overview of current delivery systems in cancer gene therapy. $J$ Control Release. 2004;94(1):1-14. doi:10.1016/j.jconrel.2003.09.013.

7. Giacca M, Zacchigna S. Virus-mediated gene delivery for human gene therapy. $J$ Control Release. 2012;161(2):377-388. doi:10.1016/j.jconrel.2012.04.008.

8. Brown MD, Schätzlein AG, Uchegbu IF. Gene delivery with synthetic (non viral) carriers. Int J Pharm. 2001;229(1-2):1-21. doi:10.1016/S0378-5173(01)00861-4.

9. Nakanishi W, Minami K, Kumar L, Ji Q, Hill JP, Ariga K. ScienceDirect Bioactive nanocarbon assemblies: Nanoarchitectonics and applications. Nano Today. 2014;9(3):378-394. doi:10.1016/j.nantod.2014.05.002.

10. Yang D, Ma P, Hou Z, Cheng Z, Li C, Lin J. Current Advances in Lanthanide Ion (Ln3+)-Based Upconversion Nanomaterials for Drug Delivery. Royal Society of Chemistry; 2015. doi:10.1039/C4CS00155A.

11. Ariga K, Kawakami K, Ebara M, Kotsuchibashi Y, Ji Q, Hill JP. Bioinspired nanoarchitectonics as emerging drug delivery systems. New J Chem. 2014;38(11):5149-5163. doi:10.1039/C4NJ00864B.

12. Daraee H, Etemadi A, Kouhi M, et al. Application of liposomes in medicine and drug delivery. Artif Cells, Nanomedicine, Biotechnol. 2016;44(1):381-391. doi:10.3109/21691401.2014.953633.

13. Bunker A, Magarkar A, Viitala T. Rational design of liposomal drug delivery systems, a review: Combined experimental and computational studies of lipidmembranes, liposomes and their PEGylation. Biochim Biophys Acta. 2016;1858:2334-2352. doi:10.1016/j.bbamem.2016.02.025.

14. Thomas CE, Ehrhardt A, Kay MA. Progress and problems with the use of viral 
vectors for gene therapy. Nat Rev Genet. 2003;4(5):346-358.

doi:10.1038/nrg1066.

15. Lv H, Zhang S, Wang B, Cui S, Yan J. Toxicity of cationic lipids and cationic polymers in gene delivery. $J$ Control Release. 2006;114(1):100-109.

doi:10.1016/j.jconrel.2006.04.014.

16. Suk JS, Xu Q, Kim N, Hanes J, Ensign LM. PEGylation as a strategy for improving nanoparticle-based drug and gene delivery. Adv Drug Deliv Rev. 2016;99:28-51. doi:10.1016/j.addr.2015.09.012.

17. Silva AKA, Di Corato R, Pellegrino T, et al. Cell-derived vesicles as a bioplatform for the encapsulation of theranostic nanomaterials. Nanoscale. 2013;5(23):1137411384. doi:10.1039/c3nr01541f.

18. Vader P, Mol EA, Pasterkamp G, Schiffelers RM. Extracellular vesicles for drug delivery. Adv Drug Deliv Rev. 2016;In Press. doi:10.1016/j.addr.2016.02.006.

19. Tominaga N, Yoshioka Y, Ochiya T. A novel platform for cancer therapy using extracellular vesicles. Adv Drug Deliv Rev. 2015;95:50-55.

doi:10.1016/j.addr.2015.10.002.

20. Zhang B, Wee R, Yeo Y, Tan KH, Lim SK. Focus on Extracellular Vesicles : Therapeutic Potential of Stem Cell-Derived Extracellular Vesicles. 2016. doi:10.3390/ijms17020174.

21. Théry C, Zitvogel L, Amigorena S. Exosomes: composition, biogenesis and function. Nat Rev Immunol. 2002;2(8):569-579. doi:10.1038/nri855.

22. Valadi H, Ekström K, Bossios A, Sjöstrand M, Lee JJ, Lötvall JO. Exosomemediated transfer of mRNAs and microRNAs is a novel mechanism of genetic 
exchange between cells. Nat Cell Biol. 2007;9(6):654-659. doi:10.1038/ncb1596.

23. Tian Y, Li S, Song J, et al. A doxorubicin delivery platform using engineered natural membrane vesicle exosomes for targeted tumor therapy. Biomaterials. 2014;35(7):2383-2390. doi:10.1016/j.biomaterials.2013.11.083.

24. Lamichhane TN, Sokic S, Schardt JS, Raiker RS, Lin JW, Jay SM. Emerging Roles for Extracellular Vesicles in Tissue Engineering and Regenerative Medicine. Tissue Eng Part B Rev. 2015;21(1):45-54.

doi:10.1089/ten.teb.2014.0300.

25. Tan S, Wu T, Zhang D, Zhang Z. Cell or Cell Membrane-Based Drug Delivery Systems. Theranostics. 2015;5(8):863-881. doi:10.7150/thno.11852.

26. Sezgin E, Kaiser H-J, Baumgart T, Schwille P, Simons K, Levental I. Elucidating membrane structure and protein behavior using giant plasma membrane vesicles. Nat Protoc. 2012;7(6):1042-1051. doi:10.1038/nprot.2012.059.

27. Zeng F, Yang W, Huang J, Chen Y, Chen Y. Determination of the lowest concentrations of aldehyde fixatives for completely fixing various cellular structures by real-time imaging and quantification. Histochem Cell Biol. 2013;139(5):735-749. doi:10.1007/s00418-012-1058-5.

28. Sun D, Zhuang $X$, Xiang $X$, et al. A novel nanoparticle drug delivery system: the anti-inflammatory activity of curcumin is enhanced when encapsulated in exosomes. Mol Ther. 2010;18(9):1606-1614. doi:10.1038/mt.2010.105.

29. Pascucci L, Coccè V, Bonomi A, et al. Paclitaxel is incorporated by mesenchymal stromal cells and released in exosomes that inhibit in vitro tumor growth: A new approach for drug delivery. J Control Release. 2014;192:262-270. 
doi:10.1016/j.jconrel.2014.07.042.

30. Alvarez-Erviti L, Seow Y, Yin H, Betts C, Lakhal S, Wood MJ a. Delivery of siRNA to the mouse brain by systemic injection of targeted exosomes. Nat Biotechnol. 2011;29(4):341-345. doi:10.1038/nbt.1807.

31. Katsuda T, Kosaka N, Takeshita F, Ochiya T. The therapeutic potential of mesenchymal stem cell-derived extracellular vesicles. Proteomics. 2013;13(1011):1637-1653. doi:10.1002/pmic.201200373.

32. Smith JA, Ng KS, Mead BE, et al. Extracellular Vesicles: Commercial Potential As Byproducts of Cell Manufacturing for Research and Therapeutic Use. Bioprocess Int. 2015;13(4):1-13.

33. Fuhrmann G, Herrmann IK, Stevens MM. Cell-derived vesicles for drug therapy and diagnostics: Opportunities and challenges. Nano Today. 2015;10(3):397-409. doi:10.1016/j.nantod.2015.04.004.

34. Vlassov A V., Magdaleno S, Setterquist R, Conrad R. Exosomes: Current knowledge of their composition, biological functions, and diagnostic and therapeutic potentials. Biochim Biophys Acta - Gen Subj. 2012;1820(7):940-948. doi:10.1016/j.bbagen.2012.03.017.

35. Whitford W, Ludlow JW, Cadwell JJS. Continuous Production of Exosomes. Genet Eng Biotechnol News. 2015;35(16).

36. EL Andaloussi S, Mäger I, Breakefield XO, Wood MJ a. Extracellular vesicles: biology and emerging therapeutic opportunities. Nat Rev Drug Discov. 2013;12(5):347-357. doi:10.1038/nrd3978.

37. van Dommelen SM, Vader P, Lakhal S, et al. Microvesicles and exosomes: 
opportunities for cell-derived membrane vesicles in drug delivery. J Control Release. 2012;161(2):635-644. doi:10.1016/j.jconrel.2011.11.021.

38. Braicu C, Tomuleasa C, Monroig P, Cucuianu A, Berindan-Neagoe I, Calin GA. Exosomes as divine messengers: are they the Hermes of modern molecular oncology? Cell Death Differ. 2015;22(1):34-45. doi:10.1038/cdd.2014.130.

39. György B, Szabó TG, Pásztói M, et al. Membrane vesicles, current state-of-theart: emerging role of extracellular vesicles. Cell Mol Life Sci. 2011;68(16):26672688. doi:10.1007/s00018-011-0689-3.

40. J. Simpson R, Mathivanan S. Extracellular Microvesicles: The Need for Internationally Recognised Nomenclature and Stringent Purification Criteria. $J$ Proteomics Bioinform. 2012;5(2):10000. doi:10.4172/jpb.10000e10.

41. Février B, Raposo G. Exosomes: endosomal-derived vesicles shipping extracellular messages. Curr Opin Cell Biol. 2004;16(4):415-421. doi:10.1016/j.ceb.2004.06.003.

42. Gesierich S, Berezovskiy I, Ryschich E, Zo M. Systemic Induction of the Angiogenesis Switch by the Tetraspanin D6/CO-029. Cancer Res. 2006;66(14):7083-7095. doi:10.1158/0008-5472.CAN-06-0391.

43. Riteau B, Faure F, Menier C, et al. Exosomes bearing HLA-G are released by melanoma cells. Hum Immunol. 2003;64(11):1064-1072. doi:10.1016/j.humimm.2003.08.344.

44. Dolo V, Li R, Dillinger M, et al. Enrichment and localization of ganglioside G(D3) and caveolin-1 in shed tumor cell membrane vesicles. Biochim Biophys Acta. 2000;1486(2-3):265-274. http://www.ncbi.nlm.nih.gov/pubmed/10903477. 
45. Akers JC, Gonda D, Kim R, Carter BS, Chen CC. Biogenesis of extracellular vesicles (EV): exosomes, microvesicles, retrovirus-like vesicles, and apoptotic bodies. J Neurooncol. 2013;113(1):1-11. doi:10.1007/s11060-013-1084-8.

46. Szajnik M, Czystowska M, Szczepanski MJ, Mandapathil M, Whiteside TL. Tumor-derived microvesicles induce, expand and up-regulate biological activities of human regulatory T cells (Treg). PLoS One. 2010;5(7):e11469. doi:10.1371/journal.pone.0011469.

47. Kim SH, Lechman ER, Bianco N, et al. Exosomes derived from IL-10-treated dendritic cells can suppress inflammation and collagen-induced arthritis. $J$ Immunol. 2005;174(10):6440-6448. doi:10.4049/jimmunol.174.10.6440.

48. Gatti S, Bruno S, Deregibus MC, et al. Microvesicles derived from human adult mesenchymal stem cells protect against ischaemia-reperfusion-induced acute and chronic kidney injury. Nephrol Dial Transplant. 2011;26(5):1474-1483. doi:10.1093/ndt/gfr015.

49. Cantaluppi V, Gatti S, Medica D, et al. Microvesicles derived from endothelial progenitor cells protect the kidney from ischemia-reperfusion injury by microRNAdependent reprogramming of resident renal cells. Kidney Int. 2012;82(4):412-427. doi:10.1038/ki.2012.105.

50. Cai Z, Yang F, Yu L, et al. Activated T Cell Exosomes Promote Tumor Invasion via Fas Signaling Pathway. J Immunol. 2012;188(12):5954-5961. doi:10.4049/jimmunol.1103466.

51. Bruno S, Grange C, Collino F, et al. Microvesicles derived from mesenchymal stem cells enhance survival in a lethal model of acute kidney injury. PLoS One. 
2012;7(3):e33115. doi:10.1371/journal.pone.0033115.

52. Ratajczak J, Miekus K, Kucia M, et al. Embryonic stem cell-derived microvesicles reprogram hematopoietic progenitors: evidence for horizontal transfer of mRNA and protein delivery. Leukemia. 2006;20(5):847-856. doi:10.1038/sj.leu.2404132.

53. Camussi G, Deregibus M, Bruno S, Grange C, Fonsato V. Exosome / microvesicle-mediated epigenetic reprogramming of cells. Am J Cancer Res. 2011;1(1):98-110 .

54. Wahlgren J, Karlson TDL, Brisslert M, et al. Plasma exosomes can deliver exogenous short interfering RNA to monocytes and lymphocytes. Nucleic Acids Res. 2012;40(17):e130-e130. doi:10.1093/nar/gks463.

55. Baj-Krzyworzeka M, Szatanek R, Weglarczyk K, et al. Tumour-derived microvesicles carry several surface determinants and mRNA of tumour cells and transfer some of these determinants to monocytes. Cancer Immunol Immunother. 2006;55(7):808-818. doi:10.1007/s00262-005-0075-9.

56. Liu C, Yu S, Zinn K, et al. Murine Mammary Carcinoma Exosomes Promote Tumor Growth by Suppression of NK Cell Function. J Immunol. 2006;176(3):1375-1385. doi:10.4049/jimmunol.176.3.1375.

57. Fairchild PJ. Immunological Tolerance: Methods and Protocols. Totowa, NJ: Humana Press Inc.; 2007.

58. Hedlund M, Nagaeva O, Kargl D, Baranov V, Mincheva-Nilsson L. Thermal- and oxidative stress causes enhanced release of NKG2D ligand-bearing immunosuppressive exosomes in leukemia/lymphoma T and B cells. PLoS One. 2011;6(2):e16899. doi:10.1371/journal.pone.0016899. 
59. Skokos D, Botros HG, Demeure C, et al. Mast Cell-Derived Exosomes Induce Phenotypic and Functional Maturation of Dendritic Cells and Elicit Specific Immune Responses In Vivo 1. J Immunol. 2003;170:3037-3045. doi:10.4049/jimmunol.170.6.3037.

60. Théry C, Clayton A, Amigorena S, Raposo G. Isolation and Characterization of Exosomes from Cell Culture Supernatants and Biological Fluids. In: Current Protocols in Cell Biology.; 2006:3.22.1-3.22.29.

61. Witwer KW, Buza EI, Bernis LT, et al. Standardization of sample collection, isolation and analysis methods in extracellular vesicle research. J Extracell Vesicles. 2013;2(20360):1-25.

62. Tauro BJ, Greening DW, Mathias RA, et al. Comparison of ultracentrifugation, density gradient separation, and immunoaffinity capture methods for isolating human colon cancer cell line LIM1863-derived exosomes. Methods. 2012;56:293304. doi:10.1016/j.ymeth.2012.01.002.

63. Momen-heravi F, Balaj L, Alian S, et al. Current methods for the isolation of extracellular vesicles. Biol Chem. 2013;394(10):1253-1262. doi:10.1515/hsz2013-0141.

64. Lamparski HG, Metha-damani A, Yao J, et al. Production and characterization of clinical grade exosomes derived from dendritic cells. J Imm. 2002;270:211-226.

65. Bobri A, Colombo M, Krumeich S, Raposo G, Thery C. Diverse subpopulations of vesicles secreted by different intracellular mechanisms are present in exosome preparations obtained by differential ultracentrifugation. J Extracell Vesicles. 2012;1(18397):1-11. 
66. Alvarez ML, Khosroheidari M, Ravi RK, Distefano JK. Comparison of protein, microRNA, and mRNA yields using different methods of urinary exosome isolation for the discovery of kidney disease biomarkers. Kidney Int. 2012;82:1024-1032. doi:10.1038/ki.2012.256.

67. Zhang Z, Wang C, Li T, Zhe L, Li L. Comparison of ultracentrifugation and density gradient separation methods for isolating Tca8113 human tongue cancer cell linederived exosomes. Oncol Lett. 2014;8:1701-1706. doi:10.3892/ol.2014.2373.

68. Simpson RJ, Lim JWE, Moritz RL, Mathivanan S. Exosomes: proteomic insights and diagnostic potential. Expert Rev Proteomics. 2009;6(3):267-283.

69. Kanwar SS, Dunlay CJ, Simeone DM, Nagrath S. Microfluidic device (ExoChip) for on-chip isolation, quantification and characterization of circulating exosomes. Lab Chip. 2014;14:1891-1900. doi:10.1039/c4lc00136b.

70. Wubbolts R, Leckie RS, Veenhuizen PTM, et al. Proteomic and Biochemical Analyses of Human B Cell-derived Exosomes. J Biol Chem. 2003;278(13):1096310972. doi:10.1074/jbc.M207550200.

71. Clayton A, Court J, Navabi H, et al. Analysis of antigen presenting cell derived exosomes, based on immuno-magnetic isolation and flow cytometry. $\mathrm{J}$ Immunol Methods. 2001;247:163-174.

72. Chen C, Skog J, Hsu C-H, et al. Microfluidic isolation and transcriptome analysis of serum microvesicles. Lab Chip. 2010;10(4):505-511. doi:10.1039/b916199f.

73. He M, Crow J, Roth M, Godwin AK. Lab on a Chip Integrated immunoisolation and protein analysis of circulating exosomes using microfluidic technology. Lab Chip. 2014;14:3773-3780. doi:10.1039/C4LC00662C. 
74. Davies RT, Kim J, Jang C, Choi E, Gho S, Park J. Lab on a Chip Microfluidic filtration system to isolate extracellular vesicles from blood. Lab Chip. 2012;12:5202-5210. doi:10.1039/c2lc41006k.

75. Voldman J. Electrical Forces For Microscale Cell Manipulation. Annu Rev Biomed Eng. 2006;8:425-454. doi:10.1146/annurev.bioeng.8.061505.095739.

76. Liu ZW, Wu H, Fine D, et al. Ciliated micropillars for the microfluidic-based isolation of nanoscale lipid vesicles. Lab Chip. 2013;13:2879-2882. doi:10.1039/c3lc41343h.

77. Lee K, Shao H, Weissleder R, Lee H. Acoustic Purification of Extracellular Microvesicles. ACS Nano. 2015;9(3):2321-2327.

78. Kadiu I, Narayanasamy P, Dash PK, Zhang W, Gendelman HE. Biochemical and Biologic Characterization of Exosomes and Microvesicles as Facilitators of HIV-1 Infection in Macrophages. J Immunol. 2016;189:744-754. doi:10.4049/jimmunol.1102244.

79. Enderle D, Spiel A, Coticchia CM, et al. Characterization of RNA from Exosomes and Other Extracellular Vesicles Isolated by a Novel Spin Column-Based Method. PLoS One. 2015:1-19. doi:10.1371/journal.pone.0136133.

80. Gardiner C, Ferreira YJ, Dragovic RA, Redman CWG, Sargent IL. Extracellular vesicle sizing and enumeration by nanoparticle tracking analysis. J Extracell Vesicles. 2013;2(19671):1-11.

81. Kastelowitz N, Yin H. Exosomes and Microvesicles: Identification and Targeting By Particle Size and Lipid Chemical Probes. ChemBioChem. 2014;15:923-928. doi:10.1002/cbic.201400043. 
82. Soo CY, Song Y, Campbell EC, Riches AC, Gunn- F, Powis SJ. Nanoparticle tracking analysis monitors microvesicle and exosome secretion from immune cells. Immunology. 2012;136:192-197. doi:10.1111/j.1365-2567.2012.03569.x.

83. Dragovic RA, Gardiner C, Brooks AS, et al. Sizing and phenotyping of cellular vesicles using Nanoparticle Tracking Analysis. Nanomedicine Nanotechnology, Biol Med. 2011;7(6):780-788. doi:10.1016/j.nano.2011.04.003.

84. Robert S, Lacroix R, Poncelet P, et al. High-Sensitivity Flow Cytometry Provides Access to Standardized Measurement of Small-Size Microparticles — Brief Report. Arter Thromb Vasc Biol. 2012;32:1054-1058.

doi:10.1161/ATVBAHA.111.244616.

85. van der Pol E, Hoekstra AG, Sturk A, Otto C, van Leeuwen TG, Nieuwland R. Optical and non-optical methods for detection and characterization of microparticles and exosomes. J Thromb Haemost. 2010;8:2596-2607. doi:10.1111/j.1538-7836.2010.04074.x.

86. Rupert LM, La C, Eldh M, et al. Determination of Exosome Concentration in Solution Using Surface Plasmon Resonance Spectroscopy. Anal Chem. 2014;86:5929-5936.

87. Im H, Shao H, Park Y II, et al. Label-free detection and molecular profiling of exosomes with a nano-plasmonic sensor. Nat Biotechnol. 2014;32(5):490-495. doi:10.1038/nbt.2886.

88. Turiák L, Misják P, Szabó TG, et al. Proteomic characterization of thymocytederived microvesicles and apoptotic bodies in BALB / c mice. J Proteomics. 2011;74(10):2025-2033. doi:10.1016/j.jprot.2011.05.023. 
89. Conde-vancells J, Rodriguez-suarez E, Embade N, et al. Characterization and Comprehensive Proteome Profiling of Exosomes Secreted by Hepatocytes. $J$ Proteome. 2008;7:5157-5166.

90. Llorente A, Skotland T, Sylvänne T, et al. Molecular lipidomics of exosomes released by PC-3 prostate cancer cells. Biochim Biophys Acta. 2013;1831:13021309. doi:10.1016/j.bbalip.2013.04.011.

91. Abels ER, Breakefield XO. Introduction to Extracellular Vesicles: Biogenesis, RNA Cargo Selection, Content, Release, and Uptake. Cell Mol Neurobiol. 2016;36(3):301-312. doi:10.1007/s10571-016-0366-z.

92. Zaborowski MP, Balaj L, Breakefield XO, Lai CP. Extracellular Vesicles: Composition, Biological Relevance, and Methods of Study. Bioscience. 2015;65(8):783-797. doi:10.1093/biosci/biv084.

93. Rupert DLM, Claudio V, Lässer C, Bally M. Methods for the physical characterization and quantification of extracellular vesicles in biological samples. Biochim Biophys Acta. 2016;In Press. doi:10.1016/j.bbagen.2016.07.028.

94. Lee Y, El Andaloussi S, Wood MJA. Exosomes and microvesicles: extracellular vesicles for genetic information transfer and gene therapy. Hum Mol Genet. 2012;21(R1):R125-34. doi:10.1093/hmg/dds317.

95. Skog J, Wurdinger T, Rijn S Van, et al. Glioblastoma microvesicles transport RNA and protein that promote tumor growth and provide diagnostic biomarkers. Nat Cell Biol. 2008;10(12):1470-1476. doi:10.1038/ncb1800.Glioblastoma.

96. Chaput N, Taieb J, Schartz NEC, Andre F, Angevin E, Zitvogel L. Exosome-based immunotherapy. Cancer Immunol Immunother. 2004;53(3):234-239. 
doi:10.1007/s00262-003-0472-x.

97. Albanese J, Meterissian S, Kontogiannea M, et al. Biologically active Fas antigen and its cognate ligand are expressed on plasma membrane-derived extracellular vesicles. Blood. 1998;91(10):3862-3874.

http://www.ncbi.nlm.nih.gov/pubmed/9573024.

98. Obregon C, Rothen-Rutishauser B, Gitahi SK, Gehr P, Nicod LP. Exovesicles from Human Activated Dendritic Cells Fuse with Resting Dendritic Cells, Allowing Them to Present Alloantigens. Am J Pathol. 2006;169(6):2127-2136. doi:10.2353/ajpath.2006.060453.

99. Théry C, Ostrowski M, Segura E. Membrane vesicles as conveyors of immune responses. Nat Rev Immunol. 2009;9(8):581-593. doi:10.1038/nri2567.

100. Chaput N, Théry C. Exosomes: immune properties and potential clinical implementations. Semin Immunopathol. 2011;33(5):419-440. doi:10.1007/s00281010-0233-9.

101. Savina A, Furlan M, Vidal M, Colombo MI. Exosome Release Is Regulated by a Calcium-dependent Mechanism in K562 Cells. J Biol Chem. 2003;278(22):2008320090. doi:10.1074/jbc.M301642200.

102. Distler JHW, Pisetsky DS, Huber LC, Kalden JR, Gay S, Distler O. Microparticles as regulators of inflammation: Novel players of cellular crosstalk in the rheumatic diseases. Arthritis Rheum. 2005;52(11):3337-3348. doi:10.1002/art.21350.

103. Fauré J, Lachenal G, Court M, et al. Exosomes are released by cultured cortical neurones. Mol Cell Neurosci. 2006;31(4):642-648.

doi:10.1016/j.mcn.2005.12.003. 
104. Krämer-Albers E-M, Bretz N, Tenzer S, et al. Oligodendrocytes secrete exosomes containing major myelin and stress-protective proteins: Trophic support for axons? Proteomics - Clin Appl. 2007;1(11):1446-1461.

doi:10.1002/prca.200700522.

105. Miyoshi H, Umeshita K, Sakon M, et al. Calpain activation in plasma membrane bleb formation during tert-butyl hydroperoxide-induced rat hepatocyte injury. Gastroenterology. 1996;110(6):1897-1904.

doi:10.1053/gast.1996.v110.pm8964416.

106. King HW, Michael MZ, Gleadle JM. Hypoxic enhancement of exosome release by breast cancer cells. BMC Cancer. 2012;12(1):421. doi:10.1186/1471-2407-12421.

107. Wysoczynski M, Ratajczak MZ. Lung cancer secreted microvesicles: underappreciated modulators of microenvironment in expanding tumors. Int $J$ Cancer. 2009;125(7):1595-1603. doi:10.1002/ijc.24479.

108. Parolini I, Federici C, Raggi C, et al. Microenvironmental pH Is a Key Factor for Exosome Traffic in Tumor Cells. J Biol Chem. 2009;284(49):34211-34222. doi:10.1074/jbc.M109.041152.

109. de Jong OG, Verhaar MC, Chen $\mathrm{Y}$, et al. Cellular stress conditions are reflected in the protein and RNA content of endothelial cell-derived exosomes. J Extracell Vesicles. 2012;1(0):1-12. doi:10.3402/jev.v1i0.18396.

110. Scott RE, Perkins RG, Zschunke M a, Hoerl BJ, Maercklein PB. Plasma membrane vesiculation in 3T3 and SV3T3 cells. I. Morphological and biochemical characterization. J Cell Sci. 1979;35:229-243. 
111. Scott RE. Plasma membrane vesiculation: a new technique for isolation of plasma membranes. Science. 1976;194(4266):743-745. doi:10.1126/science.982044.

112. Dalle-Donne I, Rossi R, Milzani A, Di Simplicio P, Colombo R. The Actin Cytoskeleton Response To Oxidants: From Small Heat Shock Protein Phosphorylation To Changes in the Redox State of Actin Itself. Free Radic Biol Med. 2001;31(12):1624-1632.

113. Charras GT, Hu C-K, Coughlin M, Mitchison TJ. Reassembly of contractile actin cortex in cell blebs. J Cell Biol. 2006;175(3):477-490. doi:10.1083/jcb.200602085.

114. Rafelski SM, Theriot JA. Crawling Toward a Unified Model of Cell Motility: Spatial and Temporal Regulation of Actin Dynamics. Annu Rev Biochem. 2004;73(1):209239. doi:10.1146/annurev.biochem.73.011303.073844.

115. Hagmann J, Burger MM, Dagan D. Regulation of plasma membrane blebbing by the cytoskeleton. J Cell Biochem. 1999;73(4):488-499. doi:10.1002/(SICI)10974644(19990615)73:4<488::AID-JCB7>3.0.CO;2-P.

116. Kosaka N, Iguchi H, Yoshioka $\mathrm{Y}$, et al. Secretory Mechanisms and Intercellular Transfer of MicroRNAs in Living Cells. 2010;285(23):17442-17452. doi:10.1074/jbc.M110.107821.

117. Akao $\mathrm{Y}$, lio $\mathrm{A}$, Itoh $\mathrm{T}$, et al. Microvesicle-mediated RNA molecule delivery system using monocytes/macrophages. Mol Ther. 2011;19(2):395-399. doi:10.1038/mt.2010.254.

118. Saari H, Lázaro-ibáñez E, Viitala $T$, Vuorimaa-laukkanen E, Siljander $P$, Yliperttula M. Microvesicle- and exosome-mediated drug delivery enhances the cytotoxicity of Paclitaxel in autologous prostate cancer cells. J Control Release. 
2015;220:727-737. doi:10.1016/j.jconrel.2015.09.031.

119. Hood JL, Scott MJ, Wickline SA. Maximizing exosome colloidal stability following electroporation. Anal Biochem. 2014;448:41-49. doi:10.1016/j.ab.2013.12.001.

120. Haney MJ, Klyachko NL, Zhao Y, et al. Exosomes as drug delivery vehicles for Parkinson's disease therapy. J Control Release. 2015;207:18-30.

doi:10.1016/j.jconrel.2015.03.033.

121. Munoz JL, Bliss S a, Greco SJ, Ramkissoon SH, Ligon KL, Rameshwar P. Delivery of Functional Anti-miR-9 by Mesenchymal Stem Cell-derived Exosomes to Glioblastoma Multiforme Cells Conferred Chemosensitivity. Mol Ther Nucleic Acids. 2013;2(April):e126. doi:10.1038/mtna.2013.60.

122. Ohno S, Takanashi M, Sudo K, et al. Systemically Injected Exosomes Targeted to EGFR Deliver Antitumor MicroRNA to Breast Cancer Cells. Mol Ther. 2012;21(1):185-191. doi:10.1038/mt.2012.180.

123. Alhasan $\mathrm{AH}$, Patel PC, Choi $\mathrm{CHJ}$, Mirkin $\mathrm{CA}$. Exosome encased spherical nucleic acid gold nanoparticle conjugates as potent microRNA regulation agents. Small. 2014;10(1):186-192. doi:10.1002/smll.201302143.

124. Fuhrmann G, Serio A, Mazo M, Nair R, Stevens MM. Active loading into extracellular vesicles significantly improves the cellular uptake and photodynamic effect of porphyrins. J Control Release. 2014;205:35-44.

doi:10.1016/j.jconrel.2014.11.029.

125. Hung ME, Leonard JN. Stabilization of exosome targeting peptides via engineered glycosylation. J Biol Chem. 2015;290:8166-8172. doi:10.1074/jbc.M114.621383. 
126. Wang E, Ascierto PA, Stroncek DF. Developments in T Cell Based Cancer Immunotherapies. 2015.

127. Kooijmans SAA, Go C, Roffler SR, Solinge WW Van, Vader P, Schiffelers RM. Display of GPI-anchored anti-EGFR nanobodies on extracellular vesicles promotes tumour cell targeting. J Extracell Vesicles. 2016;5:1-11.

128. Pegtel DM, Cosmopoulos K, Thorley-Lawson DA, et al. Functional delivery of viral miRNAs via exosomes. Proc Natl Acad Sci U S A. 2010;107(14):6328-6333. doi:10.1073/pnas.0914843107.

129. Liu Y, Li D, Liu Z, et al. Targeted exosome-mediated delivery of opioid receptor Mu siRNA for the treatment of morphine relapse. Sci Rep. 2015;5(November):17543. doi:10.1038/srep17543.

130. Momen-Heravi F, Bala S, Bukong T, Szabo G. Exosome-mediated delivery of functionally active miRNA-155 inhibitor to macrophages. Nanomedicine Nanotechnology, Biol Med. 2014;10(7):1517-1527. doi:10.1016/j.nano.2014.03.014.

131. Hung ME, Leonard JN. A platform for actively loading cargo RNA to elucidate limiting steps in EV-mediated delivery. J Extracell Vesicles. 2016;5(31027):1-13. doi:10.3402/jev.v5.31027.

132. Shimoda A, Ueda K, Nishiumi S, et al. Exosomes as nanocarriers for systemic delivery of the Helicobacter pylori virulence factor CagA. Sci Rep. 2016;6:18346. doi:10.1038/srep18346.

133. Aspe JR, Osterman CJD, Jutzy JMS, Deshields S, Whang S, Wall NR. Enhancement of Gemcitabine sensitivity in pancreatic adenocarcinoma by novel 
exosome-mediated delivery of the Survivin-T34A mutant. 2014;1:1-9.

134. Jang SC, Kim OY, Yoon CM, et al. Bioinspired Exosome-Mimetic Nanovesicles for Targeted Delivery of Chemotherapeutics to Malignant Tumors. 2013;(9):76987710.

135. Munagala R, Aqil F, Jeyabalan J, Gupta RC. Bovine milk-derived exosomes for drug delivery. Cancer Lett. 2016;371(1):48-61. doi:10.1016/j.canlet.2015.10.020.

136. Bartolini E, lanni E, Frigimelica E, et al. Recombinant outer membrane vesicles carrying Chlamydia muridarum HtrA induce antibodies that neutralize chlamydial infection in vitro. J Extracell Vesicles. 2013;2(20181):1-14.

137. Cheng Y, Schorey JS. Exosomes carrying mycobacterial antigens can protect mice against an M. tuberculosis Infection. Eur J Immunol. 2013;43(12):32793290. doi:10.1097/MPG.0b013e3181a15ae8.Screening.

138. Mahaweni NM, Kaijen-Lambers MEH, Dekkers J, Aerts JGJ V, Hegmans JPJJ. Tumour-derived exosomes as antigen delivery carriers in dendritic cell-based immunotherapy for malignant mesothelioma. J Extracell vesicles. 2013;2:1-6. doi:10.3402/jev.v2i0.22492.

139. Viaud S, Thery C, Ploix S, et al. Dendritic cell-derived exosomes for cancer immunotherapy: What's next? Cancer Res. 2010;70(4):1281-1285. doi:10.1158/0008-5472.CAN-09-3276.

140. Colino J, Snapper CM. Exosomes from bone marrow dendritic cells pulsed with diphtheria toxoid preferentially induce type 1 antigen-specific $\lg G$ responses in naive recipients in the absence of free antigen. J Immunol. 2006;177(6):37573762. doi:10.4049/jimmunol.177.6.3757. 
141. del Cacho E, Gallego M, Lee SH, et al. Induction of protective immunity against Eimeria tenella infection using antigen-loaded dendritic cells (DC) and DC-derived exosomes. Vaccine. 2011;29(21):3818-3825. doi:10.1016/j.vaccine.2011.03.022. 